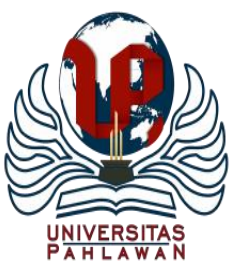

Jurnal Basicedu Volume 4 Nomor 3 Tahun 2020 Halm. 754 - 764 JURNAL BASICEDU

Research \& Learning in Elementary Education https://jbasic.org/index.php/basicedu/index

\title{
Kepuasan Kerja Intrinsik Memediasi Pengaruh Kompetensi Kerja Dan Lingkungan Kerja Pada Kinerja Guru di Sekolah Dasar
}

\author{
Aris Tri Haryanto ${ }^{1}$, Septiana Novita Dewi ${ }^{2}$, Siti Fatonah ${ }^{3}$ \\ STIE Adi Unggul Bhirawa Surakarta ${ }^{1,2,3}$ \\ E-mail : arisharyanto26@yahoo.co.id ${ }^{1}$ septianadewi25@yahoo.co.id ${ }^{2}$ siti.fatonah@ stie-aub.ac.id ${ }^{3}$
}

\begin{abstract}
Abstrak
Penelitian ini bertujuan untuk menguji secara empiris kepuasan kerja intrinsik memediasi kompetensi kerja dan lingkungan kerja terhadap kinerja Guru SD di Gugus 1 Sidoharjo Kabupaten Sragen. Populasi dalam penelitian ini adalah guru di SD Gugus 1 Sidoharjo Kabupaten Sragen sejumlah 72 guru, dengan teknik sampel sensus, sehingga jumlah sampel sebanyak 72 responden. Hasil Uji Hipotesis kompetensi kerja berpengaruh positif dan signifikan terhadap kepuasan kerja intrinsik. Lingkungan kerja berpengaruh negatif dan tidak signifikan terhadap kepuasan kerja intrinsik. Kompetensi kerja berpengaruh positif dan signifikan terhadap kinerja. Lingkungan kerja berpengaruh positif dan signifikan terhadap kinerja. Kepuasan kerja intrinsik berpengaruh positif dan signifikan terhadap kinerja. Hasil uji $\mathrm{F}$ dapat disimpulkan secara bersama-sama variabel bebas berpengaruh signifikan terhadap kinerja guru SD Gugus 1 Sidoharjo Kabupaten Sragen. Hasil nilai $\mathrm{R}^{2}$ total sebesar 0,609 dapat diartikan variasi kinerja guru SD Gugus 1 Sidoharjo Kabupaten Sragen dijelaskan oleh variabel kompetensi kerja, lingkungan kerja, dan kepuasan kerja intrinsik sebagai variabel intervening sebesar 60,9\% dan sisanya 39,1\% dijelaskan variabel lain diluar model penelitian sebagai contoh budaya organisasi, pengawasan, dan insentif. Hasil analisis jalur menunjukkan bahwa dari analisis jalur dapat diperoleh kesimpulan bahwa pengaruh langsung kompetensi kerja adalah jalur yang efektif untuk meningkatkan kinerja.
\end{abstract}

Kata kunci: kompetensi kerja, lingkungan kerja, kepuasan kerja intrinsik, kinerja

\begin{abstract}
This study aims to empirically examine intrinsic job satisfaction mediating work competence and the work environment on the performance of elementary school teachers in Cluster 1 Sidoharjo, Sragen Regency. The population in this study were 72 elementary school teachers in Sidoharjo, Sragen regency, with a census sample technique, so that the total sample was 72 respondents. Hypothesis Test Results work competence has a positive and significant effect on intrinsic job satisfaction. The work environment has a negative and not significant effect on intrinsic job satisfaction. Work competence has a positive and significant effect on performance. The work environment has a positive and significant effect on performance. Intrinsic job satisfaction has a positive and significant effect on performance. The F test results can be concluded together that the independent variables have a significant effect on the performance of elementary school teachers in the Sidoharjo Cluster 1 Sragen Regency. The results of the total $R 2$ value of 0.609 can be interpreted as variations in the performance of elementary school teachers in Sidoharjo Cluster 1 Sragen Regency explained by variables of work competence, work environment, and intrinsic job satisfaction as intervening variables by $60.9 \%$ and the remaining $39.1 \%$ are explained by other variables outside the research model for example organizational culture, supervision and incentives. The path analysis results show that from the path analysis it can be concluded that the direct effect of work competence is an effective path to improve performance.
\end{abstract}

Keywords: work competence, work environment, intrinsic job satisfaction, performance

Copyright (c) 2020 Aris Tri Haryanto, Septiana Novita Dewi, Siti Fatonah

$\triangle$ Corresponding author :

Address : Perum Graha Sine Asri Sragen, Sumber Asri, Sine, Sragen

Email : arisharyanto26@yahoo.co.id

ISSN 2580-3735 (Media Cetak)

DOI: https://doi.org/10.31004/basicedu.v4i3.426 
755 Kepuasan Kerja Intrinsik Memediasi Pengaruh Kompetensi Kerja Dan Lingkungan Kerja Pada Kinerja Guru di Sekolah Dasar- Aris Tri Haryanto, Septiana Novita Dewi, Siti Fatonah

DOI: https://doi.org/10.31004/basicedu.v4i3.426

\section{PENDAHULUAN}

Di era reformasi dan perkembangan jaman globalisasi sumber daya manusia merupakan pemberdayaan yang paling utama dalam sekolah. Dengan berbagai tantangan yang terjadi di dalam sekolah dan aktivitas menejemen berjalan dengan baik, institunsi harus memiliki guru yang berpengetahuan dan berketerampilan tinggi serta usaha untuk mengelola institusi seoptimal mungkin sehingga kinerja guru dapat meningkat. Kinerja guru merupakan hasil atau prestasi kerja guru yang dinilai dari segi kualitas maupun kuantitas berdasarkan standar kerja yang ditentukan oleh pihak sekolah. Kinerja yang baik adalah kinerja yang sesuai standar sekolah dan mendukung tercapainya tujuan sekolah. Sekolah yang baik adalah sekolah yang berusaha meningkatkan kemampuan sumber daya manusianya, karena hal tersebut merupakan faktor kunci untuk meningkatkan kinerja guru.

Peningkatan kinerja guru akan membawa kemajuan bagi sekolah untuk dapat bertahan dalam menjalankan roda pemerintahan. Oleh karena itu upaya-upaya untuk meningkatkan kinerja guru merupakan tantangan manajemen yang paling serius karena keberhasilan untuk mencapai tujuan dari misi dan visi sekolah tergantung pada kualitas kinerja sumber daya manusia yang ada didalamnya. Semakin baik kinerja, sangat mendukung produktivitas maupun tujuan organisasai. Semakin banyak guru yang mempunyai kinerja baik, akan semakin meningkatkan produktivitas sekolah secara keseluruhan akan meningkat sehingga sekolah pemerintah akan dapat menjalankan pekerjaan yang ingin dicapai di dalam kegiatan sekolah.

Guru dituntut untuk mampu menyelesaikan tugas dan tanggung jawabnya secara efektif dan efisien. Keberhasilan guru dapat diukur melalui kepuasan konsumen, berkurangnya jumlah keluhan dan tercapainya target yang optimal untuk melayani masayarakat. Menurut Handoko (2013) kinerja guru juga dapat diukur melalui penyelesaian tugasnya secara efektif dan efisien serta melakukan peran dan fungsinya dan itu semua berhubungan linear dan berhubungan positif bagi keberhasilan suatu kantor desa sebagai lembaga pemerintah di bawah kecamatan. Terdapat faktor negatif yang dapat menurunkan kinerja guru. Diantaranya adalah menurunnya keinginan guru untuk mencapai prestasi kerja, kurangnya ketepatan waktu dalam penyelesaian pekerjaan sehingga kuarang menaati peraturan. Pengaruh yang berasal dari lingkungannya, teman sekerja yang juga menurun semangatnya dan tidak adanya contoh yang harus dijadikan acuan didalam pencapaian prestasi kerja yang baik. Tingkat keabsenan didalam kehadiran, tingkat kepuasan, kehadiran selalu terlambat dan pulang tidak tepat waktu hampir setiap kantor desa. Semua itu merupakan sebab menurunnya kinerja guru dalam bekerja. Menurut Mathis dan Jackson (2011), kinerja adalah apa yang dilakukan guru, sehingga ada yang mempengaruhi kombinasi guru sekolah antara lain: kuantitas output, kualitas output, jangka waktu output, kehadiran ditempat kerja, dan sikap koperatif. Kinerja yang tinggi sangatlah diharapkan oleh sekolah. Semakin banyak guru yang mempunyai kinerja tinggi, maka 
756 Kepuasan Kerja Intrinsik Memediasi Pengaruh Kompetensi Kerja Dan Lingkungan Kerja Pada Kinerja Guru di Sekolah Dasar- Aris Tri Haryanto, Septiana Novita Dewi, Siti Fatonah

DOI: https://doi.org/10.31004/basicedu.v4i3.426

produktivitas sekolah secara keseluruhan akan meningkat sehingga sekolah akan dapat menjalankan roda pemerintahan yang ingin dicapai di dalam melayani masyarakat.

Menurut Handoko (2009) kinerja juga dapat diukur melalui penyelesaian tugasnya secara efektif dan efisien serta melakukan peran dan fungsinya dan itu semua berhubungan linear dan berhubungan positif bagi keberhasilan kinerjanya. Faktor negatif yang dapat menurunkan kinerja guru, seperti menurun keinginan guru untuk mencapai prestasi kerja, kurangnya ketepatan waktu dalam penyelesaian pekerjaan sehingga kurang menaati peraturan. Pengaruh yang berasal dari lingkungannya, teman sekerja yang juga menurun semangatnya dan tidak adanya contoh yang harus dijadikan acuan di dalam pencapaian prestasi kerja yang baik. Atas dasar fenomena serta teori yang dikemukan oleh para ahli, maka dalam penelitian ini akan dikaji lebih mendalam berkaitan dengan kinerja guru pada SD Gugus 1 Sidoharjo Kabupaten Sragen.

Faktor yang mempengaruhi kinerja guru adalah kepuasan kerja. Menurut Davis (2014) mengemukakan bahwa kepuasan kerja adalah kondisi kesukaan atau ketidaksukaan menurut pandangan guru terhadap pekerjaannya, sedangkan menurut Luthans (2012) mengemukakan bahwa kepuasan kerja intrinsik adalah suatu keadaan emosi seseorang yang positif maupun menyenangkan yang dihasilkan dari penilaian suatu pekerjaan atau pengalaman kerja. Faktorfaktor yang mendasar yang terkait erat dengan kinerja adalah kepuasan kerja yang berkaitan dengan kesejahteraan.
Kepuasan kerja dilatar belakangi oleh faktor-faktor, yaitu imbalan jasa, rasa aman, pengaruh antar pribadi, kondisi lingkungan kerja, kesempatan untuk pengembangan, kondisi lingkungan kerja, kesempatan untuk pengembangan dan peningkatan diri. Aspek kepuasan kerja intrinsik merupakan aspek yang dinilai sebagai aspek ekstrinsik dari sekolah, sejalan dengan konsep kepuasan kerja intrinsik tersebut, penilaian ini memfokuskan pada masalah yang berkaitan dengan aspek kepuasan kerja intrinsik dalam peningkatan kinerja guru. Hal ini didasarkan pada pemikiran Siagian (2012) yang menyatkan bahwa prestasi kerja masih dianggap sebagai pemegang peranan penting dalam pemenuhan kepuasan kerja intrinsik, karena para guru yang diliputi rasa tidak puas atas hal yang memperlemah kinerja akan memberikan dampak bagi sekolah yang bersifat negatif.

Faktor-faktor yang mempengaruhi kepuasan kerja guru pada dasarnya dapat dibedakan menjadi dua kelompok. yaitu faktor instrinsik dan faktor ekstrinsik. Faktor instrinsik adalah faktor yang berasal dari diri guru dan dibawa oleh setiap guru sejak mulai bekerja di tempat pekerjaannya. Sedangkan faktor ekstrinsik menyangkut hal-hal yang berasal dari luar diri guru, antara lain kondisi fisik lingkungan kerja, interaksinya dengan guru lain, sistem penggajian dan sebagainya. Lingkungan kerja adalah dimana guru melakukan pekerjaan sehari-hari. Lingkungan kerja yang kondusif adalah lingkungan yang dapat memberikan rasa aman dan memungkinkan para guru untuk dapat bekerja optimal sesuai dengan tujuan sekolah. Lingkungan kerja dapat 
757 Kepuasan Kerja Intrinsik Memediasi Pengaruh Kompetensi Kerja Dan Lingkungan Kerja Pada Kinerja Guru di Sekolah Dasar- Aris Tri Haryanto, Septiana Novita Dewi, Siti Fatonah

DOI: https://doi.org/10.31004/basicedu.v4i3.426

mempengaruhi emosi guru. Menurut Wright et.,al, (2012) Jika guru menyenangi lingkungan kerja dimana dia bekerja, maka guru tersebut akan betah di tempat kerjanya untuk melakukan aktivitas sehingga waktu kerja digunakan secara efektif dan optimis, prestasi kerja juga tinggi. Menurut Kartono (2005) membagi lingkungan ke dalam kedua kelompok yaitu kondisi-kondisi material dan kondisi-kondisi psikis. Dalam batasan tersebut terlihat bahwa lingkungan kerja bukan hanya menyangkut lingkungan fisik tempat bekerja saja, tetapi juga mencakup aspek-aspek fisik dan psikis yang ditimbulkan oleh lingkungan fisik maupun pekerjaan itu sendiri, akan membentuk guru terhadap lingkungan kerja. Lingkungan kerja adalah lingkungan dimana para guru tersebut bekerja. Lingkungan kerja merupakan tempat para guru melakukan pekerjaan sesuai dengan tanggung jawabnya masing-masing. Lingkungan kerja merupakan sesuatu yang berada disekitar para pekerja dan dapat mempengaruhi dirinya dalam menjalankan tugas yang dibebankan kepadanya, sehingga pembangunan dan pengembangan berarti perubahan yang dinamis, akseleratif yang berdampak positif. Salah satu aspek dalam pembangunan adalah terciptanya lingkungan kerja yang kondusif. Lingkungan kerja yang nyaman menciptakan lingkungan produktif, sehingga menyenangkan dan membuat krasan penghuninya.

Kompetensi merupakan kemampuan atau pengetahuan yang dimiliki seseorang "Competence is the ability or the knowledge of a person". Kompetensi atau kemampuan sebauh trait (bawaan atau dipelajari) yang mengijinkan seseorang mengerjakan sesuatu mental atau fisik (Robbins,
2006). Kompetensi berkaitan dengan kemampuan individu oleh karena itu efektivitas manajemen dalam sebuah organisasi akan berhasil apabila mampu mengenali perbedaan individu yang ada di dalamnya. Kompetensi dapat diartikan suatu kemampuan pelaksanaan tugas sesuai dengan ilmu pengetahuan dan ketrampilan serta teknologi dan pengalaman yang berhubungan dengan bidang tugasnya.

Kompetensi di SD Gugus 1 Sidoharjo Kabupaten Sragen selama ini masih belum optimal, hal ini disebabkan tingkat pendidikan dasar sangat memerlukan kompetensi yang berkualitas karena akan mendidik karakter anak bangsa di usia anak-anak. Tingkat pendidikan guru akan mempengaruhi cara belajar mengajar di dalam kelas dan akan mempengaruhi anak-anak didiknya. SD Gugus 1 Sidoharjo Kabupaten Sragen dalam hal kualitas sumber daya manusianya sebenanya semua guru memiliki kemampuan yang baik dalam bekerja, tetapi karena kurangnya strata pendidikan yang diselenggarakan mengakibatkan kinerja guru di SD Gugus 1 Sidoharjo Kabupaten Sragen menjadi kurang optimal. Selain itu terdapat lingkungan kerja yang kurang mendukung dalam pelaksanaan pemberdayaan sekolah, hal ini menyebabkan kinerja yang menurun, misalnya kurangnya peralatan kerja, ruang kerja yang kurang nyaman, ventilasi yang kurang dan prosedur yang tidak jelas. Pembentukan lingkungan kerja yang mendukung produktivitas kerja akan menimbulkan kepuasan kerja intrinsik bagi para guru di SD Gugus 1 Sidoharjo Kabupaten Sragen. Selain itu belum adanya kompetensi kerja yang baik, 
758 Kepuasan Kerja Intrinsik Memediasi Pengaruh Kompetensi Kerja Dan Lingkungan Kerja Pada Kinerja Guru di Sekolah Dasar- Aris Tri Haryanto, Septiana Novita Dewi, Siti Fatonah

DOI: https://doi.org/10.31004/basicedu.v4i3.426

menyebabkan guru dalam mengerjakan pekerjaan sering tidak tepat waktu, hal ini mengakibatkan kinerja guru di SD Gugus 1 Sidoharjo Kabupaten Sragen perlu ditingkatkan.

Berdasarkan uraian di atas dan dari fenomena yang ada maka perlu dilakukan penelitian dengan judul: "Kepuasan Kerja Intrinsik Memediasi Pengaruh Kompetensi Kerja dan Lingkungan Kerja Pada Kinerja (Study pada Guru SD di Gugus 1 Sidoharjo Kabupaten Sragen)".

\section{METODE}

Penelitian ini merupakan penelitian kuantitatif, yang menggunakan data primer dengan menggunakan angket atau kuesioner yang diisi oleh responden. Populasi dalam penelitian ini adalah guru di SD Gugus 1 Sidoharjo Kabupaten Sragen sejumlah 72 guru. Teknik pengambilan sampel menggunakan teknik sensus, yaitu seluruh anggota populasi dijadikan sebagai sampel. Teknik analisis yang digunakan adalah analisis jalur (Path Analysis).

\section{HASIL DAN PEMBAHASAN}

\section{Hasil Uji Instrument}

Hasil uji validitas nilai $r_{\text {hitung }}$ keseluruhan indikator yang diuji bernilai positif dan lebih besar dari nilai $r_{\text {tabel }}$ yang besarnya adalah 228. Karena keseluruhan nilai $r_{\text {hitung }}$ semua indikator yang diuji lebih besar daripada nilai $r_{\text {tabel, }}$, maka dapat di ambil kesimpulan bahwa semua butir indikator dalam penelitian ini dinyatakan valid.
Tabel 1. Hasil Uji Reliabilitas

\begin{tabular}{lcl}
\hline \multicolumn{1}{c}{ Variabel } & $\begin{array}{c}\text { Alpha } \\
\text { Cronbach }\end{array}$ & Keterangan \\
\hline Kompetensi kerja & 0,805 & Reliabel \\
Lingkungan kerja & 0,934 & Reliabel \\
Kepuasan kerja & 0,733 & Reliabel \\
intrinsik & 0,786 & Reliabel \\
Kinerja & & \\
\hline
\end{tabular}

Sumber : Data yang diolah, 2020

\section{Hasil Analisis Jalur (Path Analysis) I}

Tabel 2. Hasil Analisis Jalur Persamaan 1

\begin{tabular}{|c|c|c|c|c|c|c|}
\hline \multicolumn{7}{|c|}{ Coefficients } \\
\hline \multirow[b]{2}{*}{ Model } & & \multicolumn{2}{|c|}{$\begin{array}{l}\text { Unstandardized } \\
\text { Coefficients }\end{array}$} & \multirow{2}{*}{$\begin{array}{c}\text { Standardized } \\
\text { Coefficients } \\
\text { Beta }\end{array}$} & \multirow[b]{2}{*}{$t$} & \multirow[b]{2}{*}{ Sig. } \\
\hline & & $B$ & Std. Error & & & \\
\hline 1 & (Constant) & 16,223 & 3,015 & & 5,381 &, 000 \\
\hline & Kompetensi Kerja &, 328 &, 078 & ,451 & 4,187 & , 000 \\
\hline & Lingkungan Kerja &,- 066 & 109 &,- 065 & -600 &, 551 \\
\hline
\end{tabular}

Sumber : Data yang diolah, 2020

Dari hasil persamaan regresi pertama di atas, dijelaskan sebagai berikut:

$Y_{1}=0,451 X_{1}-0,065 X_{2}+\epsilon_{1}$

Keterangan:

1. $\beta_{1}=$ Nilai koefisien regresi kompetensi kerja sebesar 0,451, hal ini menunjukkan bahwa kompetensi kerja berpengaruh positif terhadap kepuasan kerja intrinsik Guru SD Gugus 1 Sidoharjo Kabupaten Sragen.

2. $\beta_{2}=$ Nilai koefisien regresi lingkungan kerja sebesar $-0,065$ hal ini menunjukkan bahwa lingkungan kerja berpengaruh negatif terhadap kepuasan kerja intrinsik Guru SD Gugus 1 Sidoharjo Kabupaten Sragen. 
759 Kepuasan Kerja Intrinsik Memediasi Pengaruh Kompetensi Kerja Dan Lingkungan Kerja Pada Kinerja Guru di Sekolah Dasar- Aris Tri Haryanto, Septiana Novita Dewi, Siti Fatonah

DOI: https://doi.org/10.31004/basicedu.v4i3.426

\section{Hasil Analisis Jalur (Path Analysis) 2}

Tabel 3. Hasil Analisis Jalur Persamaan 2

\begin{tabular}{|c|c|c|c|c|c|c|}
\hline \multicolumn{7}{|c|}{ Coefficients ${ }^{2}$} \\
\hline \multirow[b]{2}{*}{ Model } & & \multicolumn{2}{|c|}{$\begin{array}{c}\text { Unstandardized } \\
\text { Coefficients }\end{array}$} & \multirow{2}{*}{$\begin{array}{c}\text { Standardized } \\
\text { Coefficients }\end{array}$} & \multirow[b]{2}{*}{$t$} & \multirow[b]{2}{*}{ Sig. } \\
\hline & & B & Std. Error & & & \\
\hline 1 & $\begin{array}{l}\text { (Constant) } \\
\end{array}$ & $-1,739$ & 3,518 & &,- 494 & 6,623 \\
\hline & Kompetensi Kerja & ,479 & 086 & ,532 & 5,574 & ,000 \\
\hline & Lingkungan Kerja & 278 & 108 & 221 & 2,586 & ,012 \\
\hline & Kepuasan Kerja Intrinsik & 284 & ,118 & ,229 & 2,408 & ,019 \\
\hline
\end{tabular}

Sumber : Data yang diolah, 2020

Dari hasil persamaan regresi kedua di atas, maka dijelaskan sebagai berikut:

$Y_{2}=0,532 X_{1}+0,221 X_{2}+0,229 X_{3}+\epsilon_{2}$

Keterangan:

1. $\beta_{1}=$ Nilai koefisien regresi kompetensi kerja sebesar 0,532 hal ini menunjukkan bahwa kompetensi kerja berpengaruh positif terhadap kinerja Guru SD Gugus 1 Sidoharjo Kabupaten Sragen.

2. $\beta_{2}=$ Nilai koefisien regresi lingkungan kerja sebesar 0,221 hal ini menunjukkan bahwa lingkungan kerja berpengaruh positif terhadap kinerja Guru SD Gugus 1 Sidoharjo Kabupaten Sragen.

3. $\beta_{3}=$ koefisien regresi kepuasan kerja intrinsik sebesar 0,229 hal ini menunjukkan bahwa kepuasan kerja intrinsik berpengaruh positif terhadap kinerja Guru SD di Gugus 1 Sidoharjo Kabupaten Sragen.

\section{Hasil Uji Hipotesis}

Hasil uji hipotesis dalam penelitian ini diantaranya adalah sebagai berikut:

1. Kompetensi kerja berpengaruh signifikan terhadap kepuasan kerja intrinsik Guru SD Gugus 1 Sidoharjo Kabupaten Sragen, hal ini dapat dilihat dari nilai signifikansi yaitu 0,000 $<0,05$. (Hipotesis 1 terbukti)

2. Lingkungan kerja berpengaruh tidak signifikan terhadap Kepuasan kerja intrinsik Guru SD Gugus 1 Sidoharjo Kabupaten Sragen, hal ini dapat dilihat dari nilai signifikansi yaitu 0,551 $>0,05$. (Hipotesis 2 tidak terbukti)

3. Kompetensi kerja berpengaruh signifikan terhadap kinerja Guru SD Gugus 1 Sidoharjo Kabupaten Sragen, hal ini dapat dilihat dari nilai signifikansi yaitu $0,000<0,05$. (Hipotesis 3 terbukti)

4. Lingkungan kerja berpengaruh signifikan terhadap kinerja Guru SD Gugus 1 Sidoharjo Kabupaten Sragen, hal ini dapat dilihat dari nilai signifikansi yaitu $0,012<0,05$. (Hipotesis 4 terbukti)

5. Kepuasan kerja intrinsik berpengaruh signifikan terhadap kinerja Guru SD Gugus 1 Sidoharjo Kabupaten Sragen, hal ini dapat dilihat dari nilai signifikansi yaitu 0,019 $<0,05$.

(Hipotesis 5 terbukti).

\section{Hasil Uji F}

Tabel 4. Hasil Uji F

\begin{tabular}{|c|c|c|c|c|c|c|}
\hline \multicolumn{7}{|c|}{ ANOV $A^{b}$} \\
\hline Model & & $\begin{array}{c}\text { Sum of } \\
\text { Squares }\end{array}$ & $d f$ & Mean Square & $\mathrm{F}$ & \\
\hline \multirow[t]{3}{*}{1} & Regression & 160,333 & 3 & 53,444 & 23,455 &, $000^{\mathrm{a}}$ \\
\hline & Residual & 154,945 & 68 & 2,279 & & \\
\hline & Total & 315,278 & 71 & & & \\
\hline
\end{tabular}

Sumber : Data yang diolah, 2020

Hasil uji secara serempak (Uji F) pada persamaan kedua diketahui besarnya nilai $\mathrm{F}=$ 23,455 signifikansi $0,000<0,05$, sehingga dapat disimpulkan secara bersama-sama variabel bebas 
760 Kepuasan Kerja Intrinsik Memediasi Pengaruh Kompetensi Kerja Dan Lingkungan Kerja Pada Kinerja Guru di Sekolah Dasar- Aris Tri Haryanto, Septiana Novita Dewi, Siti Fatonah

DOI: https://doi.org/10.31004/basicedu.v4i3.426

berpengaruh signifikan terhadap Kinerja Guru SD Gugus 1 Sidoharjo Kabupaten Sragen.

\section{Hasil Uji Koefisien Determinasi}

Hasil nilai $\mathrm{R}^{2}$ total sebesar 0,609 dapat diartikan variasi kinerja Guru SD Gugus 1 Sidoharjo Kabupaten Sragen dijelaskan oleh variabel kompetensi kerja, lingkungan kerja, dan kepuasan kerja intrinsik sebagai variabel intervening sebesar $60,9 \%$ dan sisanya $39,1 \%$ dijelaskan variabel lain diluar model penelitian sebagai contoh budaya organisasi, pengawasan, dan insentif.

\section{Hasil Perhitungan Pengaruh Langsung dan}

\section{Tidak Langsung}

Tabel 5. Koefisien Jalur

\begin{tabular}{|c|c|c|c|c|c|}
\hline \multirow[t]{2}{*}{ Dari Variabel } & \multicolumn{2}{|c|}{ Koefisien Jalur } & \multirow{2}{*}{$\begin{array}{l}\text { Total } \\
\text { Effect }\end{array}$} & \multirow[t]{2}{*}{ t-test } & \multirow{2}{*}{$\begin{array}{c}\text { p- } \\
\text { value }\end{array}$} \\
\hline & $\begin{array}{l}\text { Direct } \\
\text { Effect }\end{array}$ & $\begin{array}{c}\text { Indirect } \\
\text { Effect }\end{array}$ & & & \\
\hline $\begin{array}{l}\text { Kompetensi } \\
\text { kerja } \rightarrow \\
\text { Kinerja }\end{array}$ & $\begin{array}{l}\mathrm{P}_{3} \\
=0,532\end{array}$ & & & & \\
\hline $\begin{array}{l}\text { Lingkungan } \\
\text { kerja } \rightarrow \\
\text { Kinerja }\end{array}$ & $\begin{array}{l}\mathrm{P}_{4} \\
=0,221\end{array}$ & & & & \\
\hline $\begin{array}{l}\text { Kompetensi } \\
\text { kerja } \rightarrow \\
\text { Kepuasan } \\
\text { kerja intrinsik } \\
\rightarrow \text { Kinerja }\end{array}$ & & $\begin{array}{l}P_{1} \times P_{5} \\
=0,451 \\
x 0,229 \\
=0,103\end{array}$ & $\begin{array}{l}P_{3}+\left(P_{1} x\right. \\
\left.P_{5}\right) \\
=0,532+ \\
0,103 \\
=0,635\end{array}$ & 1.839 & 0.065 \\
\hline $\begin{array}{l}\text { Lingkungan } \\
\text { kerja } \rightarrow \\
\text { Kepuasan } \\
\text { kerja intrinsik } \\
\Rightarrow \text { Kinerja }\end{array}$ & & $\begin{array}{l}P_{2} \times P_{5} \\
=-0,065 \\
x 0,229 \\
=-0,014\end{array}$ & $\begin{array}{l}P_{4}+\left(P_{2} x\right. \\
\left.P_{5}\right) \\
=0,221+ \\
(-0,014) \\
=0,207\end{array}$ & $\overline{0.570}$ & 0.568 \\
\hline
\end{tabular}

Sumber : Data yang diolah, 2020

Berdasarkan tabel di atas hubungan antar variabel dapat digambarkan sebagai berikut:

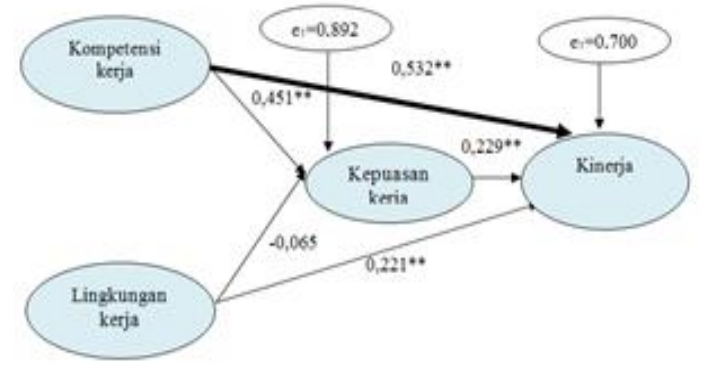

\section{Gambar 1. Pengaruh Langsung dan Tidak} Langsung

Sumber : Data yang diolah, 2020

1. Pengaruh Kompetensi kerja terhadap kinerja

Analisis jalur menunjukkan bahwa penggunaan variabel intervening kepuasan kerja intrinsik dalam rangka peningkatan kinerja, untuk variabel kompetensi kerja adalah tidak efektif, karena pengaruh langsung menghasilkan pengaruh yang yang lebih besar. Hal ini berarti, untuk meningkatkan kinerja Guru SD Gugus 1 Sidoharjo Kabupaten Sragen sebaiknya memperhatikan faktor-faktor dalam meningkatkan Kompetensi kerja agar dapat meningkatkan kepuasan kerja intrinsik Guru SD di Gugus 1 Sidoharjo Kabupaten Sragen yang pada akhirnya dapat meningkatkan kinerja Guru SD di Gugus 1 Sidoharjo Kabupaten Sragen. Dengan kompetensik mampu menjembatani Guru SD maka akan berimbas semakin meningkatnya kepuasan kerja intrinsik dalam menjalankan tugasnya, dengan kepuasan kerja intrinsik yang tinggi menyebabkan kenerja Guru SD yang tinggi pula kemudian kepuasan kerja intrinsik yang meningkat akan berpengaruh positif terhadap kinerja Guru SD. 
761 Kepuasan Kerja Intrinsik Memediasi Pengaruh Kompetensi Kerja Dan Lingkungan Kerja Pada Kinerja Guru di Sekolah Dasar- Aris Tri Haryanto, Septiana Novita Dewi, Siti Fatonah

DOI: https://doi.org/10.31004/basicedu.v4i3.426

Dengan adanya peningkatan kepuasan kerja intrinsik tersebut, diharapkan kepuasan kerja intrinsik kerja Guru SD Gugus 1 Sidoharjo Kabupaten Sragen akan meningkat dan pada akhirnya akan meningkatkan kinerja Guru SD. Upaya untuk meningkatkan indikator kompetensi Guru SD agar meningkat dapat dilakukan antara lain : Meningkatkan tingkat pendidikan guru yang lebih tinggi, karena hal akan lebih meningkatkan kompetensi guru dalam mengajar, misalnya guru mengikuti studi lanjut ke jenajang yang lebih tinggi. Guru SD melakukan pekerjaan dengan cepat dan cermat, misalnya memahami karakter anak didiknya, sehingga dapat memperlakukan mereka dengan tepat. Guru SD mudah memahami tugas yang diberikan secara tertulis maupun lisan, misalnya memahami job description dengan baik.

2. Pengaruh Lingkungan kerja terhadap kinerja Penggunaan variabel intervening kepuasan kerja intrinsik dalam rangka peningkatan kinerja, untuk variabel lingkungan kerja adalah tidak efektif, karena pengaruh tidak langsung menghasilkan pengaruh yang lebih kecil dari pada pengaruh langsung. Hal ini berarti, untuk meningkatkan kinerja Guru SD Gugus 1 Sidoharjo Kabupaten Sragen sebaiknya memperhatikan variabel lingkungan kerja, untuk meningkatkan kinerja Guru SD di Gugus 1 Sidoharjo Kabupaten Sragen.

Dengan adanya peningkatan lingkungan kerja tersebut, diharapkan kepuasan kerja intrinsik kerja Guru SD Gugus 1 Sidoharjo
Kabupaten Sragen akan meningkat dan pada akhirnya akan meningkatkan kinerja Guru SD. Upaya untuk meningkatkan indikator Guru SD agar lingkungan kerja meningkat dapat dilakukan antara lain : Interaksi dengan teman kerja cukup terjaga dengan baik, misalnya menjaga hubungan dengan penuh kekeluargaan dengan sesama guru. Sirkulasi udara diruang kerja saya cukup baik, sehingga nyaman untuk bekerja, misalnya adanya fasilitas AC di dalam ruang guru maupun diruang kelas. Adanya pencahayaan yang terang di ruangan guru bekerja, sehingga memudahkan bekerja, misalnya adanya penerangan yang cukup.

\section{SIMPULAN}

1. Hasil Uji Hipotesis adalah:

a. Kompetensi kerja berpengaruh positif dan signifikan terhadap kepuasan kerja intrinsik Guru SD Gugus 1 Sidoharjo Kabupaten Sragen.

b. Lingkungan kerja berpengaruh negatif dan tidak signifikan terhadap kepuasan kerja intrinsik Guru SD Gugus 1 Sidoharjo Kabupaten Sragen.

c. Kompetensi kerja berpengaruh positif dan signifikan terhadap kinerja Guru SD Gugus 1 Sidoharjo Kabupaten Sragen.

d. Lingkungan kerja berpengaruh positif dan signifikan terhadap Kinerja Guru SD Gugus 1 Sidoharjo Kabupaten Sragen.

e. Kepuasan kerja intrinsik berpengaruh positif dan signifikan terhadap Kinerja Guru SD Gugus 1 Sidoharjo Kabupaten Sragen. 
762 Kepuasan Kerja Intrinsik Memediasi Pengaruh Kompetensi Kerja Dan Lingkungan Kerja Pada Kinerja Guru di Sekolah Dasar- Aris Tri Haryanto, Septiana Novita Dewi, Siti Fatonah

DOI: https://doi.org/10.31004/basicedu.v4i3.426

2. Hasil analisis jalur menunjukkan bahwa Dari analisis jalur dapat diperoleh kesimpulan bahwa pengaruh langsung kompetensi kerja adalah jalur yang efektif untuk meningkatkan kinerja.

Adapun saran yang dapat diberikan yaitu

1. Kompetensi kerja melalui kepuasan kerja intrinsik merupakan variabel yang paling dominan mempengaruhi kinerja Guru SD Gugus 1 Sidoharjo Kabupaten Sragen. Untuk itu pihak Gugus 1 Sidoharjo Kabupaten Sragen sebaiknya lebih meningkatkan kompetensi kerja intrinsik dapat dilakukan seperti melihat nilai indikator tertinggi pada uji validitas kompetensi kerja, misalnya:

a. Meningkatkan tingkat pendidikan guru yang lebih tinggi, karena hal akan lebih meningkatkan kompetensi guru dalam mengajar, misalnya guru mengikuti studi lanjut ke jenajang yang lebih tinggi.

b. Guru SD melakukan pekerjaan dengan cepat dan cermat, misalnya memahami karakter anak didiknya, sehingga dapat memperlakukan mereka dengan tepat.

a. Guru SD mudah memahami tugas yang diberikan secara tertulis maupun lisan, misalnya memahami job description dengan baik.

b. Variabel lingkungan kerja perlu diperhatikan karena berpengaruh negatif dan tidak signifikan terhadap kepuasan intrinsik.

\section{DAFTAR PUSTAKA}

Dwi Agung Nugroho Arianto (2013). Pengaruh Kedisiplinan, Lingkungan Kerja Dan Budaya Kerja Terhadap Kinerja tugas Tenaga Pengajar. Jurnal Economia, Volume 9, Nomor 2, Oktober 2013

Dyer, Lee, dan Donald F Parker, (2010), Classfying Outcomes in Work Motivating Research: An Examination of The Intrinsic dan Extrinsic Dichotomy, "Journal of Applied Psichology, 455-458.

Edi, (2010). Pengaruh Kompetensi kerja Terhadap Motivasi Dan Kepuasan kerja intrinsik Serta Kinerja tugas Guru Pada Sub Sektor Industri Pengolahan Kayu Skala Menengah Di Jawa Timur. Jurnal Manajemen \& Kewirausahaan, VOL. 7, NO. 2, September 2005: 171-188

Haryadi Sarjono, Lim Sanny, Sheftian Pancha Cahyo (2013). Review of Organizational Culture, Style Leadership Affect Job Satisfaction on Employee Performance at PT. Motor Nasional. Jakarta Based Approach SPSS vs LISREL Global Network Journal, Vol. 5 No. 1 March 2012 p.36-57

Hendrawan, 2012, Pengaruh pendidikan pelatihan, kepuasan kerja dan komunikasi terhadap kinerja melalui budaya organisasi di Pemkab Semarang, Bisnis dan Manajemen Unisbank Semarang. Vol 23. No.3 hal. 45 65

Ideswal,Yahya dan Hanif Alkadri. (2020). Kontribusi Iklim Sekolah Dan Kepemimpinan Kepala Sekolah Terhadap Kinerja Guru Sekolah Dasar. Jurnal Basicedu Vol 4 No 2 April 2020 p-ISSN 2580-3735 e-ISSN 2580-1147 DOI: 10.31004/basicedu.v4i2.381

I Wayan Mudiartha Utama (2012). Pengaruh Motivasi, Lingkungan Kerja, Kompetensi Dan Kompensasi Terhadap Kepuasan kerja intrinsik Dan Kinerja tugas Di Lingkungan Kantor Dinas Pekerjaan Umum Provinsi Bali Anak Agung Ngurah Bagus Dhermawan, I Gde Adnyana Sudibya. 
763 Kepuasan Kerja Intrinsik Memediasi Pengaruh Kompetensi Kerja Dan Lingkungan Kerja Pada Kinerja Guru di Sekolah Dasar- Aris Tri Haryanto, Septiana Novita Dewi, Siti Fatonah

DOI: https://doi.org/10.31004/basicedu.v4i3.426

Jurnal Manajemen, Strategi Bisnis, dan Kewirausahaan Vol. 6, No. 2 Agustus 2012

Leonard, Robert W. College (2012). The impact of corpora organizing and leader Behavior on satisfaction in nonprofits. Journal of Occupational and Organizational Psychology. Proceedings of ASBBS. Vol.19. No.1

Linawati Dan Suhaji (2014). Pengaruh Motivasi, Kompetensi, Kepemimpinan, Dan Lingkungan Kerja Terhadap Kinerja tugas Guru (Studi Pada PT. Herculon Carpet Semarang).

http//jurnal.widyamanggala.ac.id/index.php/ wmkeb/article/ 2014. Sekolah Tinggi Ilmu Ekonomi Widya Manggala.

Luthans F., 2012, Organizational Behavioural, 7th Edition, McGraw-Hill, New York. Macy B. A., M. F. Peterson, \& L. W. Norton, 1989, "A Test of Participation Theory in a Work Redesign Field Setting: Degree of Participation and Comparation Site Contracts", Human Relation, 42(12): 1095 1165 .

Mangkunegara, Anwar Prabu. 2014. Manajemen Sumber Daya Manusia. Bandung: Remaja Rosda Karya.

Moenir, 2014. Metodologi Penelitian, Aplikasi dalam Pemasaran, Jakarta : Penerbit PT Gramedia Pustaka Utama

Nitisemito, Alex. 2010, Management Personalia (Manajemen Sumber Daya Manusia), sasamito Bros, Bandung.

Ostroff, 2013. Relationship between Satisfaction, attitude and performance an organization level analisis". Journal of Applied Psycology, Vol:77, No.6, p.933-973

Reza Amelia (2013). Pengaruh Kompetensi kerja Dan Stres Kerja Terhadap Kinerja tugas Melalui Kepuasan kerja intrinsik Sebagai Variabel Intervening ( Studi Pada Bank Mandiri Cabang Padang). http://journal.fekon.unand.ac.id/Jurnal FE Universitas Andalas Vol. 1 (2013) No. 1
Sartika (2010). Analisis Pengaruh disiplin kerja, Kompetensi kerja Terhadap Kinerja tugas Guru Dengan Kepuasan kerja intrinsik Sebagai Variabel Intervening (Studi pada PT. Coca Cola Amatil Indonesia (Central Java). Jurnal Bisnis \& Manajemen, Vol 3. No. 2 p.81-93

Sarwono, Jonathan. 2010. Analisis Jalur Untuk Bisnis dengan SPSS. Penerbit Andi Offset:Yogyakarta.

Schein E., 2014, Organizational Culture and Leadership, San Frasisco Jossey Bass.

Sedarmayanti. 2012. Tata Kerja dan Produktivitas Kerja Suatu Tinjauan dari Aspek Ergonomi atau Kaitan antara Manusia dengan Lingkungan Kerja, Bandung : Mandar Maju.

Simamora, Henry. 2014. Manajemen Sumber Daya Manusia. Edisi kedua Sekolah Tinggi Ilmu Ekonomi (YKPN). Yogyakarta.

Siswanto, 2013,Riset Sumber Daya Manusia, Jakarta:PT. Gramedia Pustaka Utama

Sri Iswahyuni (2014). Pengaruh Lingkungan Kerja dan Disiplin Kerja Terhadap Kinerja tugas Guru dengan Kepuasan kerja intrinsik Sebagai Variabel Intervning Pada Unit Pelaksana Teknis Daerah Dinas Pertanian Kabupaten Klaten. Tesis STIE-AUB Surakarta

Slamet Widodo (2014). Pengaruh Lingkungan Kerja dan Disiplin Kerja Terhadap Kinerja tugas dengan Kepuasan kerja intrinsik Sebagai Variabel Intervning Pada Unit Pelaksana Teknis Daerah Dinas Pertanian Kabupaten Klaten. Tesis STIE-AUB Surakarta

Stephanie Tanto Kurniawan, Faustine (2014). Pengaruh Komunikasi Dan Kepuasan kerja intrinsik Guru Terhadap Kinerja tugas Guru Departemen Front Office Hotel "X" Surabaya. Jurnal Hospitality dan Manajemen Jasa Vol. 1 Tahun 2015. http://studentjournal.petra.ac.id 
764 Kepuasan Kerja Intrinsik Memediasi Pengaruh Kompetensi Kerja Dan Lingkungan Kerja Pada Kinerja Guru di Sekolah Dasar- Aris Tri Haryanto, Septiana Novita Dewi, Siti Fatonah

DOI: https://doi.org/10.31004/basicedu.v4i3.426

Stoner, James A.F, 2011. Management, Third Edition. Prentice-Hall International Inc.Englewood.Chlips.New Jersey

Syufriati dan Gustina, (2020). Peningkatan Kompetensi Pedagogik Guru Dalam Membuat Perencanaan Pembelajaran Melalui Supervisi Akademik. Jurnal Basicedu Vol 4 No 2 April 2020 p-ISSN 2580-3735 e-ISSN 2580-1147 DOI: $\underline{10.31004 / \text { basicedu.v4i2.360 }}$

Yafang Tsai, (2011). Relationship between Organizational Culture, Leadership Behavior and Job Satisfaction. Tsai BMC Health Services Research 2011, 11:98 